\title{
BMJ Open Choice architecture interventions to improve diet and/or dietary behaviour by healthcare staff in high-income countries: a systematic review
}

\author{
Lena Al-Khudairy, ${ }^{1}$ Olalekan A Uthman, ${ }^{1}$ Rosemary Walmsley, ${ }^{1,2}$ \\ Samantha Johnson, ${ }^{1}$ Oyinlola Oyebode ${ }^{1}$
}

To cite: Al-Khudairy L, Uthman OA, Walmsley R, et al. Choice architecture interventions to improve diet and/or dietary behaviour by healthcare staff in high-income countries: a systematic review. BMJ Open 2019;9:e023687. doi:10.1136/ bmjopen-2018-023687

- Prepublication history and additional material for this paper are available online. To view these files, please visit the journal online (http://dx.doi. org/10.1136/bmjopen-2018023687).

Received 26 April 2018 Revised 28 September 2018 Accepted 23 November 2018

Check for updates

(c) Author(s) (or their employer(s)) 2019. Re-use permitted under CC BY. Published by BMJ.

${ }^{1}$ Warwick Medical School, University of Warwick, Coventry, UK

${ }^{2}$ Worcester College, University of Oxford, Oxford, UK

Correspondence to

Dr Oyinlola Oyebode;

0.R.0.0yebode@warwick.ac.uk

\section{ABSTRACT}

Objectives We were commissioned by the behavioural insights team at Public Health England to synthesise the evidence on choice architecture interventions to increase healthy purchasing and/or consumption of food and drink by National Health Service (NHS) staff.

Data sources MEDLINE, EMBASE, CINAHL, Cochrane Central register of Controlled Trials, PsycINF0, Applied Social Sciences Index and Abstracts and Web of Science were searched from inception until May 2017 and references were screened independently by two reviewers. Design A systematic review that included randomised experimental or intervention studies, interrupted time series and controlled before and after studies.

Participants Healthcare staff of high-income countries. Intervention Choice architecture interventions that aimed to improve dietary purchasing and/or consumption (outcomes) of staff.

Appraisal and synthesis Eligibility assessment, quality appraisal, data abstraction and analysis were completed by two reviewers. Quality appraisal of randomised trials was informed by the Cochrane Handbook, and the Risk of Bias Assessment Tool for Nonrandomized Studies was used for the remainder. Findings were narratively synthesised.

Results Eighteen studies met the inclusion criteria. Five studies included multiple workplaces (including healthcare settings), 13 were conducted in healthcare settings only. Interventions in 10 studies were choice architecture only and 8 studies involved a complex intervention with a choice architecture element. Interventions involving a proximity element (making behavioural options easier or harder to engage with) appear to be frequently effective at changing behaviour. One study presented an effective sizing intervention. Labelling alone was generally not effective at changing purchasing behaviour. Interventions including an availability element were generally reported to be successful at changing behaviour but no included study examined this element alone. There was no strong evidence for the effect of pricing on purchasing or dietary intake.

Conclusion Proximity, availability and sizing are choice architecture elements that are likely to be effective for NHS organisations.

Trial registration number CRD42017064872.
Strengths and limitations of this study

- Examines interventions appropriate to improve diet in this important and unique population group: healthcare staff

- Potential bias in identification of studies was minimised through a comprehensive search across major electronic databases relevant to the topic of this review, reference lists of relevant studies were screened and no language restriction was applied.

- To increase methodological rigour and minimise error and bias, each study included in this review was selected, assessed, data extracted and quality assessed by two review authors independently.

- Many included studies examined complex interventions, and it is not always possible to draw conclusions about the contribution of specific choice architecture elements to the outcomes.

\section{INTRODUCTION}

The leading risk behaviour for disability and death in England, as in other high-income countries, is poor diet. ${ }^{1}$ Worldwide, the proportion of adults who are overweight has increased to $36.9 \%$ of men and $38.0 \%$ in women. $^{2}$ Disease associated with poor diet costs the National Health Service (NHS) at least $£ 5.8$ billion per year. ${ }^{3}$ Nearly two-thirds of adults in England are now overweight or obese. ${ }^{4}$ The overall cost of obesity to wider society was projected to reach $£ 27$ billion in $2015 .^{5}$

Healthcare settings have an important role to play in helping their staff tackle this issue. First, obesity is associated with absenteeism, presenteeism, early retirement, injuries, discrimination and litigation. ${ }^{6-8}$ In England, NHS staff absence due to poor health costs at least $£ 2.4$ billion a year. ${ }^{9}$ Improving employee health may improve productivity and performance of the workforce leading to improved patient care. Second, health professionals 
play an important role in health promotion. However, a high proportion of healthcare staff do not engage in positive health behaviours themselves. ${ }^{1011}$ Nurses with poor health behaviour may be less likely to carry out health promotion activity. ${ }^{12}$ A questionnaire survey of 540 pre-registered nurses found that three quarters felt that their physical appearance affected how they were perceived as a nurse. ${ }^{12}$ Most respondents felt that patients would be more likely to heed their advice on health behaviours if they appeared to be following that advice themselves. $79.1 \%$ agreed that nurses should present themselves as role models for health behaviours. ${ }^{12}$ Similarly a questionnaire completed by occupational health staff found that a fifth of them felt their own weight made it difficult to address the issue in patients. ${ }^{13}$ By taking action to address diet and obesity for healthcare staff, these organisations and staff will be role models for others. While these are good reasons for any healthcare setting taking a role in supporting staff to eat healthily in the UK, an additional reason is that the NHS is the largest employer. ${ }^{14}$ This means that improving the health and well-being of the 1.4 million NHS staff will lift the health and well-being levels of the entire UK population.

The WHO defined a healthy workplace as 'one in which workers and managers collaborate to use a continual improvement process to protect and promote the health, safety and well-being of all workers and the sustainability of the workplace'. ${ }^{15}$ There are initiatives around the world to improve workplace well-being, and many of these are specific to healthcare settings. ${ }^{16}$ In England, there are a number of policy drivers to encourage and support NHS organisations to improve the food and drink environment including an NHS Commissioning for Quality and Innovation Indicator: healthy food for NHS staff, visitors and patients. ${ }^{17}$ Changing the environment to promote healthy behaviour, such as healthy food and drink purchasing and consumption, can be particularly useful and effective because

- When the environment makes healthy choices easier, this does not require any effort by the target audience. This means it is not just those people who are highly motivated to make healthy changes who benefit.

- Most changes are no-cost or low cost to introduce.

We were commissioned by the behavioural insights team at Public Health England (PHE) to undertake a systematic review and evidence synthesis, examining the literature to inform the evidence base on choice architecture interventions to increase healthier purchasing and/ or consumption of food and drink by NHS staff.

\section{MATERIALS AND METHODS}

The protocol for this systematic review was registered with PROSPERO (an international database of prospectively registered systematic reviews in health and social care) on 1 May 2017 (CRD42017064872). ${ }^{18}$

MEDLINE, EMBASE, CINAHL, Cochrane Central register of Controlled Trials, PsycINFO, Applied Social
Sciences Index and Abstracts, and Web of Science were searched from inception until May 2017. Reference lists of retrieved included studies and of identified relevant systematic reviews were scanned for any additional studies not picked up by our electronic searches. No restrictions were made by language or year of publication. The search terms used included medical subject headings or the equivalent, and text word terms (ie, health promotion, choice architecture, food services, meals, workplace). A specialist librarian (SJ) was consulted for further search terms. Searches were tailored to individual databases (please see online supplementary material 1).

Studies met the inclusion criteria if they fulfilled all of the following:

Study design: Randomised experimental or intervention studies, including cluster randomised trials, quasi-randomised studies, interrupted time series studies (before and after) and controlled before and after studies.

Participants: NHS staff or staff from any other healthcare setting in a high-income country context. We used the World Bank classification for high-income countries, which includes 79 countries in total. ${ }^{19}$

Interventions: Behavioural interventions that aimed to change dietary purchasing and/or consumption of staff were included. We restricted the specific behavioural interventions examined to "choice architecture' or 'nudge' or 'design' interventions. We used Hollands ${ }^{20}$ definition of choice architecture interventions-'those that involve altering small-scale physical and social environments, or micro-environments to cue healthier behaviour' and the associated framework to structure this review. We expanded this framework to include interventions that altered the price of items to cue healthier behaviour (table 1). This framework was chosen in discussion with PHE as it has previously been used to examine dietary interventions and was applicable to the context (healthcare settings).

Outcomes:-(a) dietary (food and/or drink) purchasing (eg, sales data; receipts analysis) in restaurants, canteens, vending machines or other situations in which food and drinks are sold; or (b) dietary intake assessed by validated tools or by more than one dietary measure such as multiple 24 hours dietary recalls. We did not examine caloric intake as self-reported measures showed poor correlation compared with objective measures for caloric intake. ${ }^{21}$

Following the database searching, titles, abstracts or both of every record retrieved were screened for potential relevance by two review authors (LA and $\mathrm{OO}$ ) independently. Studies not carried out in high-income countries, qualitative studies and studies of children were excluded at this stage. Following this preliminary screening, full reports of potentially relevant studies were obtained, and two reviewers (two of LA, OO, OU) independently assessed studies for inclusion/exclusion using a checklist form based on the four inclusion criteria above. Where there 
Table 1 Typology of choice architecture intervention in micro-environments, modified from Hollands et al ${ }^{20}$

\begin{tabular}{|c|c|}
\hline Intervention class & Intervention type \\
\hline \multirow[t]{4}{*}{ Primarily alter properties of objects or stimuli } & $\begin{array}{l}\text { Ambience-alter aesthetic or atmospheric aspects of the surrounding } \\
\text { environment }\end{array}$ \\
\hline & $\begin{array}{l}\text { Labelling - apply labelling or endorsement information to product or at point- } \\
\text { of-choice }\end{array}$ \\
\hline & Sizing - change size or quantity of the product \\
\hline & Pricing - change price of the product \\
\hline \multirow[t]{2}{*}{ Primarily alter placement of objects or stimuli } & Availability - add behavioural options within a given microenvironment \\
\hline & $\begin{array}{l}\text { Proximity - make behavioural options easier or harder to engage with, } \\
\text { requiring reduced or increased effort }\end{array}$ \\
\hline
\end{tabular}

was disagreement about the inclusion of a study, a third reviewer was consulted (LA or OO or OU). Where resolution of a disagreement was not possible, we added the article to those 'awaiting assessment' and contacted study authors for clarification. Data were extracted from the included studies by two reviewers (two of LA, OO, OU, RW) independently using a predefined and pre-piloted data abstraction form (please see online supplementary material 2). Key data included details on methods, participants, intervention (including mapping to framework domains), outcomes, funding and notable conflicts of interest of study authors. The assessment of the methodological quality of included randomised trials was informed by guidelines from the Cochrane Handbook. ${ }^{22}$ Risk of bias for other quantitative study designs used the Risk of Bias Assessment Tool for Nonrandomized Studies. ${ }^{23}$

\section{Patient and public involvement}

As this was a themed commissioned piece of work, patient and public advisors were not involved in the development of the research question, design of the study or conduct of the study. We were required to develop a toolkit (online supplementary material 3) in a companion format designed for the audience who make decisions about catering in NHS organisations. Two advisors (please see acknowledgement) reviewed the toolkit to ensure its relevance to the target audience.

\section{RESULTS}

Searching electronic databases generated 17505 hits which equated to 14294 individual records after duplicates were removed. Screening of titles and abstracts for potential relevance excluded 14120 records as they did not meet the above-mentioned inclusion criteria of this review, leaving 174 potentially relevant records.
Screening relevant systematic reviews and included studies references yielded an additional 10 records. After formal inclusion/exclusion of 184 records, we identified 28 records from 18 studies met the inclusion criteria of this review. This included nine records from five studies in which the settings were not exclusively hospitals or other healthcare workplaces, but in which at least one of the sites involved was relevant to our review. In addition, we noted 10 records from 9 studies where we were unable to ascertain whether the study met our inclusion criteria based on information included in the study reports, and author contacts received no replies. In these cases, studies were classified as 'awaiting classification' (figure 1).

Results were narratively synthesised due to the substantial heterogeneity in study design, interventions (even when classified within the same framework category) and outcomes reported. We were unable to proceed with planned meta-analysis or subgroup analyses. ${ }^{18}$

\section{Included studies}

Healthcare settings

Key characteristics of 13 included published studies are presented in table 2. Eight studies ${ }^{24-33}$ examined pure choice architecture interventions and five studies $^{34-41}$ examined complex interventions for which some elements were choice architecture. One included study was conducted in the $\mathrm{UK}^{24}$ three in other European countries, ${ }^{25} 2631$ eight in the $\mathrm{USA}^{27-30} 32-3739-41$ and one in Australia. ${ }^{38}$ Eight studies were interrupted time series, ${ }^{25} \quad 27-34 \quad 38$ two were cluster randomised controlled trials (RCTs), ${ }^{35} 36^{39-41}$ one was an RCT, ${ }^{37}$ one was a controlled before and after study ${ }^{26}$ and one cross-sectional study. ${ }^{24}$ Seven studies examined purchasing outcomes, ${ }^{25} 27-3138$ five examined dietary 


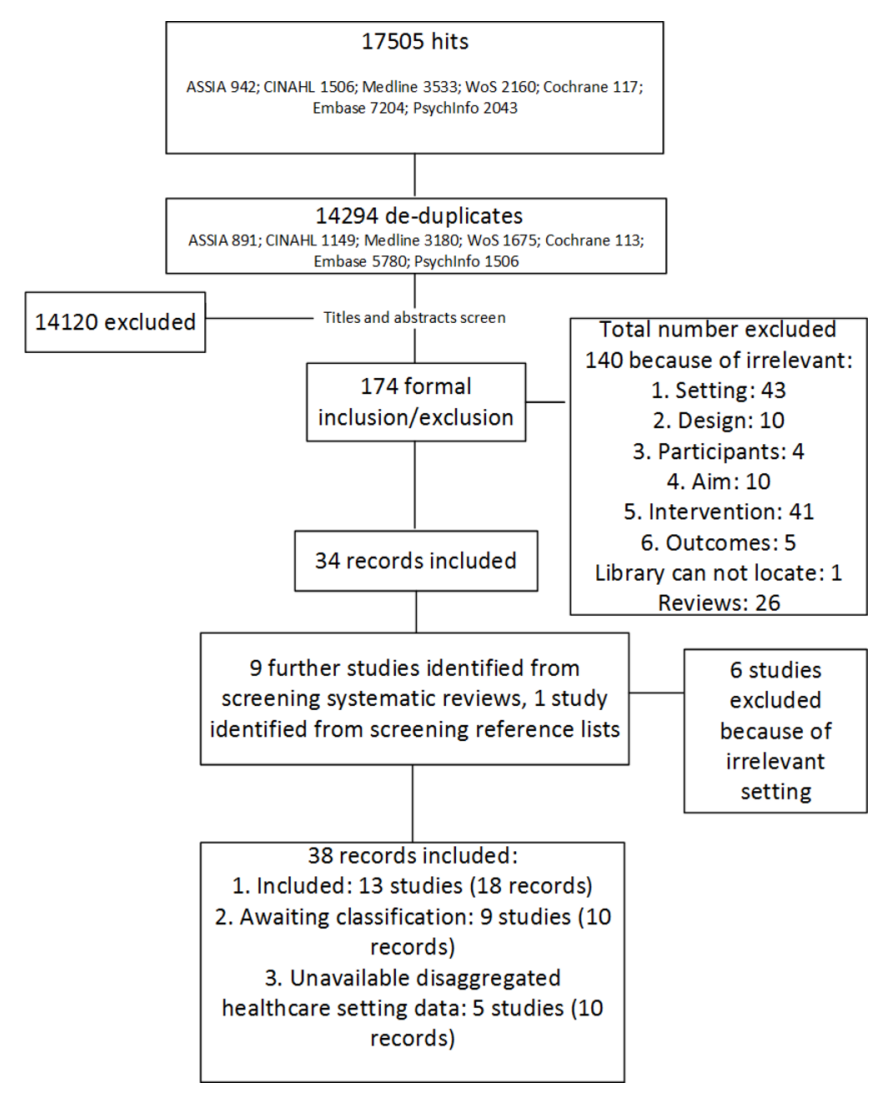

Figure 1 Preferred Reporting Items for Systematic Reviews and Meta-Analyses flow diagram.

consumption $^{24} 26$ 35-37 39-41 and one study examined both purchasing and dietary consumption. ${ }^{34}$

\section{Multiple workplaces}

Five studies (table 2) in which settings included multiple workplaces and data were not disaggregated for healthcare settings were included in this review. Two studies ${ }^{42-45}$ examined pure choice architecture interventions and three studies ${ }^{46-49}$ examined complex interventions for which some elements were choice architecture. Two studies were conducted in the USA, ${ }^{46} 47$ two in The Netherlands ${ }^{4245} 48$ and one in the UK. ${ }^{43}$ Three studies were cluster RCTs, ${ }^{42} 45-4749$ one was a controlled before and after study ${ }^{48}$ and one was a cross-sectional study. ${ }^{43}{ }^{44}$ Four studies examined dietary consumption ${ }^{43} 44$ 46-48 while one examined purchasing. ${ }^{42}$ Further details of included studies are available in table 2.

\section{Awaiting classification}

Despite contacting authors we were unable to classify nine studies because sufficient details were lacking in study reports. Five studies were unclear on the setting ${ }^{50-54}$ ; two studies were unclear on the outcomes ${ }^{55} 56$; one study was unclear on the type of participants ${ }^{57}$ and one abstract was unclear on several domains. ${ }^{58}$

\section{Intervention components and effectiveness}

We examined effectiveness of interventions in included studies by whether they were a choice architecture-only intervention or a complex intervention with choice architecture elements. Summaries of the components included in interventions mapped against their reported effectiveness are presented in tables 3 and 4 .

\section{Pure choice architecture}

Of the choice architecture-only interventions, almost all included studies involved labelling elements, including three studies that examined labelling in isolation. The most frequently studied single-element choice architecture interventions were proximity interventions, investigated in five studies. ${ }^{24} 25273031$ No included study investigated ambience or priming elements (table 3). Most of the identified published studies reported successful interventions.

There was mixed evidence for the effectiveness of labelling interventions implemented on their own. Labelling interventions were not found to have an effect on purchasing in two studies, ${ }^{25}$ although they were reported to change purchasing behaviour in one other study. ${ }^{28}$ In the study that reported successfully changing purchasing through labelling, every item of food on offer in a hospital canteen was labelled with its caloric value. This had a significant effect on the number of calories purchased during the intervention phase. This study was at low risk of bias in three domains; however, it is more than four decades old and therefore likely to be examining a slightly different context to present day. ${ }^{28}$ There was a low risk of bias in one of the studies that found no effect of labelling. ${ }^{25}$ In this study, lean (30\% less fat) and butter croissants which were similar in price, appearance and taste were on offer in a Dutch hospital restaurant, where they are a popular choice for lunch. During the intervention period, the lean basket was labelled with a sign that stated 'The saturated (unhealthy) fat content of this croissant is $30 \%$ lower'; however, there was statistically significant difference between the number or ratio of the two alternative products purchased during the intervention period compared with the control periods. ${ }^{25}$ Another study labelled the two entrees on offer in a hospital canteen (one of which was designed to be healthier) with information on their constituent calories, fat, and sodium but this did not significantly change sales of the healthier option. ${ }^{29}$ This study had a high risk of bias from confounding. ${ }^{29}$ Overall it appears that labelling is unlikely to be effective on its own.

One study, with a low risk of bias in three domains, examined an intervention which used sizing alone, specifically, offering a smaller size of the main meal of the day, which was successful in terms of changing purchasing behaviour-about $10 \%$ of hot meals sold were small meals, with no overall change in total hot meals sold and no compensatory purchasing, for instance, purchasing the smaller hot meal and adding a portion of chips. ${ }^{45} \mathrm{~A}$ pricing element was also evaluated in this study, in which the smaller meal was either priced proportionately so that both size and price of the meal were $65 \%$ of the standard; or 'value' pricing was used in which the size of the 
Table 2 Characteristics of included studies

\begin{tabular}{|c|c|c|c|}
\hline Study & Participants/worksite & Interventions & Outcomes \\
\hline Dorresteijn et $a^{25}$ & $\begin{array}{l}\text { Canteen, medical centre. } \\
\text { University Medical Centre with }>11000 \text { employees, } \\
>1000 \text { hospital beds and }>2000 \text { customers visiting the } \\
\text { hospital restaurant each day. } \\
\text { Inclusion/exclusion: N/A (data not collected from } \\
\text { individuals). }\end{array}$ & $\begin{array}{l}\text { (1) Point-of-decision prompts on hospital elevator } \\
\text { doors promoting stair use. In the hospital } \\
\text { restaurant: (2) point of- purchase prompts } \\
\text { promoting reduced-salt soup. } \\
\text { (3) Point-of-purchase prompts promoting lean } \\
\text { croissants. } \\
\text { (4) Reversal of the accessibility and availability of } \\
\text { diet margarine and butter. } \\
\text { Comparator: No comparator. }\end{array}$ & $\begin{array}{l}\text { Number and ratio of purchased normal-salt } \\
\text { soup, reduced-salt soup, croissants, lean } \\
\text { croissants purchased, diet margarine and } \\
\text { butter. }\end{array}$ \\
\hline Geaney et $a l^{67}$ & $\begin{array}{l}\text { Canteen, hospital. } \\
\text { Participants were representative sample of } 100 \text { adults } \\
\text { aged } 18-64 \text { years working in two public sector hospitals } \\
\text { ( } 50 \text { staff from each hospital). } \\
\text { Inclusion: Being an employee and consuming at least one } \\
\text { main meal in the hospital staff canteen daily. }\end{array}$ & $\begin{array}{l}\text { Restricting food high in salt, fat and sugar. } \\
\text { Modifying menus to make healthier options } \\
\text { available. Replacing purchasing orders for } \\
\text { high salt products (eg, bacon) with low salt } \\
\text { alternatives (eg, turkey). Salt removed in all } \\
\text { cooking places and tables but available in }\end{array}$ & $\begin{array}{l}\text { Macronutrients (g/day): total sugars, sucrose, } \\
\text { fructose, total fat, saturated fat, protein, } \\
\text { carbohydrates, salt. Micronutrients (mg/day): } \\
\mathrm{K}, \mathrm{Ca} \text {, Fe, vitamin B6, vitamin B12, vitamin } \\
\mathrm{C} \text {, vitamin D. }\end{array}$ \\
\hline
\end{tabular}

main meal in the hospital staff canteen daily. cooking places and tables but available in Exclusion: None reported. small sachets at service. Nutrition information on salt reduction and a healthy diet displayed. No sauces or accompaniments added without customer's consent. Staff encouraged to consume extra salad and vegetable options at no extra charge. Cooking oil use limited. All desserts fruit based.

Comparator: Canteen at another hospital with no intervention.

\begin{tabular}{|c|c|}
\hline Lassen et $a{ }^{26}$ & $\begin{array}{l}\text { Canteen, hospital. } \\
\text { The canteen was seeking Keyhole certification in } \\
\text { Denmark. Participants were canteen customers } \\
\text { approached at random after purchasing lunch. } \\
\text { Inclusion: Purchasing lunch in the canteen. } \\
\text { Exclusion: Not reported. }\end{array}$ \\
\hline Lowe et $\left.a\right|^{34}$ & $\begin{array}{l}\text { Canteens, hospitals. } \\
\text { Inclusion: Reporting eating lunch in the hospital cafeteria } \\
\text { at least two times each week, on average, being between } \\
21 \text { and } 65 \text { years of age and being a hospital or university } \\
\text { employee. } \\
\text { Exclusion: Having a current diagnosis of a chronic } \\
\text { disease or condition known to affect appetite or } \\
\text { bodyweight, taking medication known to affect appetite } \\
\text { or bodyweight, being pregnant or planning to become } \\
\text { pregnant within the next } 24 \text { months, being enrolled or } \\
\text { having plans to label within the next } 24 \text { months in an } \\
\text { organised weight management programme, and/or having } \\
\text { plans to terminate hospital employment within the next } \\
12 \text { months. }\end{array}$ \\
\hline
\end{tabular}
Introduction of the Keyhole symbol on freshly prepared food in the canteen. The Keyhole symbol is used in the Nordic countries as a sign of a healthy choice (meeting certain criteria). Comparator: No intervention.

When the intervention period began, participants in both groups were exposed to environmental change $(\mathrm{EC})$ : reductions in the energy density (ED) of some foods offered in the cafeteria and introduction of nutritional labels for all foods sold in the cafeterias.

Participants in the EC-Plus condition received two additional intervention components: training in reducing the ED of their diet and discounts on low-ED foods purchased in the cafeteria. Comparator: Environmental change only.

MacDonald et $\mathrm{al}^{38} \quad \begin{aligned} & \text { Aboriginal Community controlled health organisations. } \\ & \text { Inclusion/exclusion: Not reported. }\end{aligned}$

A tailored 'Healthy Catering Toolkits' to local caterers at each site and included order forms classified according to the 'traffic light guide' to ensure healthy catering choices were easy ordering choices for staff. They also distributed 'traffic light guide' posters and information sheets, a nutrition policy template and a walletsized card for interpreting food labels. Comparator: No comparator.

Canteen, hospital.

A hospital cafeteria that served hospital staff, students and hospital visitors.

Inclusion/exclusion: Not reported.
Desserts were arrayed in columns four deep along the cafeteria counter. On control days research assistants arrayed desserts in columns of four, high-calorie desserts alternating with lowcalorie desserts, permitting equal access to each dessert. High-calorie desserts were placed in the two front positions with low-calorie desserts in the read (less accessible) positions on days 3 and 5 . On days 2 and 4 this order was reversed. Comparator: No comparator.

\begin{tabular}{|c|c|c|}
\hline Milich $^{28}$ & $\begin{array}{l}\text { Canteen, hospital. } \\
\text { Inclusion: Being a female employee (identifiable by an ID } \\
\text { badge and/or uniform) and having a food tray. } \\
\text { Exclusion: Being a patient or visitor, being visibly pregnant } \\
\text { or being an employee who had brought food from home } \\
\text { or only bought part of her meal in the cafeteria. }\end{array}$ & $\begin{array}{l}\text { Calorie signs were posted for foods in the } \\
\text { cafeteria. } \\
\text { The intervention consisted of } 1 \text { week of price } \\
\text { increase, followed by } 1 \text { week of price increase } \\
\text { and calorie presentation. } \\
\text { Comparator: No comparator. }\end{array}$ \\
\hline Racette et $\left.a\right|^{35}$ & $\begin{array}{l}\text { Worksites, medical centre. } \\
\text { Inclusion: All employees }>18 \text { years of age were eligible, } \\
\text { including those who smoked, had pre-existing disease } \\
\text { (eg, hypertension, diabetes) or used medications. } \\
\text { Exclusion: Not reported. }\end{array}$ & $\begin{array}{l}\text { The intervention comprised a constellation } \\
\text { of nutrition components, physical activity } \\
\text { components, and incentives designed to promote } \\
\text { healthy dietary and physical activity behaviours, } \\
\text { with the goals of promoting weight control and } \\
\text { reducing risk factors for cardiovascular disease. } \\
\text { Specific intervention components included } \\
\text { weekly healthy snack cart, monthly lunchtime } \\
\text { seminars, monthly newsletters, walking maps, } \\
\text { participation cards and participation rewards. } \\
\text { Each week a registered dietitian/exercise } \\
\text { specialist was available at the worksite to provide } \\
\text { support. } \\
\text { Comparator: Health assessments only. }\end{array}$ \\
\hline
\end{tabular}

Comparator: Health assessments only.
Energy per meal consumed ( $\mathrm{kJ})$, energy density of meal $(\mathrm{kJ} / 100 \mathrm{~g})$, fat content $(\mathrm{E} \%)$, fruit and vegetables $(\mathrm{g} / 100 \mathrm{~g})$, salt $(\mathrm{g} / 100 \mathrm{~g})$, refined sugars $(\mathrm{g} / 100 \mathrm{~g})$, wholegrain $(\mathrm{g} / 100 \mathrm{~g})$.

Fruit (servings/day), vegetables (servings/day) bread products (servings/day), dairy products (servings/day), fats and sweets (servings/day), meats (servings/day);

Purchased kcal (kcal): purchased calories from fat (\%); purchased calories from protein (\%); purchased calories from carbohydrate (\%)

Proportion of purchased foods in category 'foods to limit' (\%).

\section{Dessert purchases.}

Calories bought (kcal), money spent (\$).

Fruit and vegetable intake (servings/day)

Continued 
Table 2 Continued

\begin{tabular}{|c|c|c|c|}
\hline Study & Participants/worksite & Interventions & Outcomes \\
\hline Sato et $a l^{29}$ & $\begin{array}{l}\text { Cafeteria, medical centre. } \\
\text { Customers of the medical centre cafeteria aged } 18 \text { years } \\
\text { and older. Roughly } 70 \% \text { of the customers at Kaiser } \\
\text { Permanente San Francisco Medical Center are Kaiser } \\
\text { employees; the rest are visitors or patients in the hospital. } \\
\text { The cafeteria serves roughly } 100 \text { customers per day. } \\
\text { Inclusion/exclusion: N/A (receipts collected anonymously). }\end{array}$ & $\begin{array}{l}\text { A 'Healthy Pick' option meeting various criteria } \\
\text { was made available every day. The meals } \\
\text { available were labelled with information featuring } \\
\text { calories, fat and sodium. } \\
\text { Comparator: No comparator. }\end{array}$ & $\begin{array}{l}\text { Number of Healthy Picks purchased, number } \\
\text { of main meals purchased. }\end{array}$ \\
\hline Sorensen et $a l^{3639-41}$ & $\begin{array}{l}\text { Community health centres. } \\
\text { Inclusion: Being a permanent employee and working at } \\
\text { least } 15 \text { hours a week. } \\
\text { Exclusion: Not reported. }\end{array}$ & $\begin{array}{l}\text { The core intervention included periodic exposure } \\
\text { to national 5-a-Day campaigns and a general } \\
\text { nutrition presentation. In the additional worksite } \\
\text { intervention, educational activities and changes } \\
\text { were made to the worksite environment including } \\
\text { labelling and adding fruit and vegetables to } \\
\text { vending machines. } \\
\text { Comparator: Core intervention only. }\end{array}$ & Fruit and vegetable intake (servings/day). \\
\hline
\end{tabular}

\begin{tabular}{|c|c|}
\hline Stites et $a l^{37}$ & $\begin{array}{l}\text { Canteen, hospital. } \\
\text { Inclusion: Having a body mass index of at least } 25.0 \mathrm{~kg} / \\
\mathrm{m}^{2} \text {, eating at least three lunches/week in the hospital } \\
\text { cafeteria, being willing to allow researchers to collect } \\
\text { data about their lunch purchases, and having access to a } \\
\text { computer at work. } \\
\text { Exclusion: Having a diagnosis of unstable hypertension, } \\
\text { dyslipidaemia or coronary artery disease whose medical } \\
\text { therapy had changed in the past three months, having } \\
\text { plans to terminate hospital employment within } 4 \text { months } \\
\text { following study enrolment, or being pregnant. }\end{array}$ \\
\hline Thorndike et $\left.a\right|^{303233}$ & $\begin{array}{l}\text { Canteen, hospital. } \\
\text { Hospital employees have the option of paying for } \\
\text { cafeteria purchases by direct payroll deduction using a } \\
\text { 'platinum plate' card. } \\
\text { Inclusion: Using 'platinum plate' and making a purchase } \\
\text { in the cafeteria at least three times during each 3-month } \\
\text { period from baseline to the end of follow-up. } \\
\text { Exclusion: Not reported. }\end{array}$ \\
\hline
\end{tabular}

During the Full Intervention phase participants

Kcal per lunch purchased (kcal), fat grams pe received mindful eating training, were encouraged lunch purchased $(\mathrm{g})$.

to pre-order their lunches, and were given

vouchers to use on lunch purchases. Following

this there was a Partial Intervention phase,

where participants were encouraged to preorder

their lunches but did not receive vouchers. The

preordering system listed the food available daily

in the cafeteria, along with nutritional information.

Employees had to order at least $45 \mathrm{~min}$ ahead of

scheduled pick up time.

Comparator: Wait list control.

A traffic light food labelling system was

introduced, along with signage explaining

it. Three months later further changes were

introduced, including rearranging items in the

beverage and sandwich refrigerators to put al

the green items at eye level; placing baskets

of bottled water throughout the cafeteria; and

providing pre-packaged salads next to the pizza

counter.

Comparator: No comparator.

Van Kleef ${ }^{31}$
Inclusion/exclusion: N/A.
Beresford et $\left.a\right|^{46}$
$\begin{aligned} & 28 \text { worksites (six health service organisations). } \\ & \text { Inclusion: (for worksites) Having a food-serving cafeteria } \\ & \text { and having between } 250 \text { and } 2000 \text { employees. } \\ & \text { Exclusion: N/A. }\end{aligned}$

Four successive weeks were randomly assigned to four experimental conditions:

Intervention 1: $25 \%$ of products healthy, these located at top shelves.

Intervention 2: $25 \%$ of products healthy, these located at bottom shelves.

Intervention $3: 75 \%$ of products healthy, these

located at bottom shelves.

Intervention $4: 75 \%$ of products healthy, these

located top at shelves.

Comparator: No comparator.

The intervention was tailored to worksites.

Elements included a kick-off event, the 5-a-Day

message being posted on boards in each

worksite, more fruit and vegetables becoming

part of the menus and the provision of a self-help

manual for every employee.

Comparator: No intervention.

\begin{tabular}{|c|c|c|}
\hline Holdsworth ${ }^{4344}$ & $\begin{array}{l}\text { Six worksites (two healthcare). } \\
\text { Inclusion/exclusion: Not reported. }\end{array}$ & $\begin{array}{l}\text { The Heartbeat Award scheme increases } \\
\text { opportunities for behaviour change by providing } \\
\text { customers with information, reminders and } \\
\text { reinforcement to guide them towards healthier } \\
\text { choices. } \\
\text { Comparator: No intervention. }\end{array}$ \\
\hline Kwak et $a^{4859}$ & $\begin{array}{l}12 \text { worksites (two hospitals). } \\
\text { Inclusion: Employees with body mass index }>18 \mathrm{~kg} / \mathrm{m}^{2} \text { and } \\
\text { not under any medical restrictions. } \\
\text { Exclusion: Not reported. }\end{array}$ & $\begin{array}{l}\text { There was an individual and an environmental } \\
\text { component to the intervention. Interventions } \\
\text { included changes in the assortment of food } \\
\text { products in the cafeteria, workshops, an } \\
\text { information wall containing information on the } \\
\text { balance between food intake and physical } \\
\text { activity, posters or prompts stimulating stair use, } \\
\text { and ways to form lunch-walking and cycling } \\
\text { groups. }\end{array}$ \\
\hline Sorensen et $a l^{47} 49$ & $\begin{array}{l}16 \text { worksites (at least one intervention and one control } \\
\text { site specialising in 'healthcare'). } \\
\text { Inclusion: (for worksites) Having } 200-2000 \text { employees, } \\
\text { having a cafeteria with a kitchen, having an annual } \\
\text { turnover rate of }<25 \% \text {, having }<25 \% \text { of employees } \\
\text { working rotating shifts, part time or off site and being } \\
\text { stable as a company, defined as having no plans for } \\
\text { geographic relocation or major lay-offs in the next } 2 \text { years. } \\
\text { Exclusion: Not reported. }\end{array}$ & $\begin{array}{l}\text { Worksites received a } 15 \text {-month intervention } \\
\text { with various elements. These included direct } \\
\text { education programmes, such as classes } \\
\text { offered in all intervention worksites and optional } \\
\text { activities tailored to individual worksites, and } \\
\text { environmental programmes which targeted } \\
\text { cafeterias both to increase the availability of low- } \\
\text { fat, high-fibre foods and to provide supportive } \\
\text { nutrition education by labelling those food } \\
\text { options. } \\
\text { Comparator: No intervention. }\end{array}$ \\
\hline
\end{tabular}

Of items bought: \% red, \% green (red labels and green labels as denoting unhealthy and healthy choices respectively).

Of beverages bought: \% red

$\%$ green.

Number of healthy snacks sold, number of unhealthy snacks sold. 


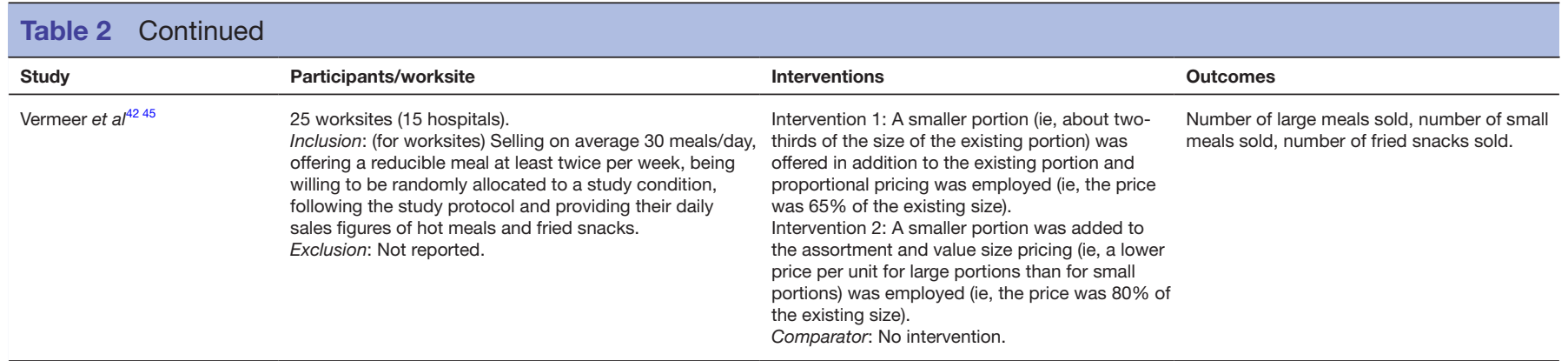

N/A, not applicable.

meal was $65 \%$ of the standard, but the price only reduced to $80 \%$ of the standard. The pricing condition did not change the effectiveness of the intervention; there was no significant different between the proportionate and value pricing conditions. ${ }^{4245}$

Proximity interventions alone were successful at changing purchasing behaviour in two studies. ${ }^{25} 27$ The interventions included having margarine available in four centrally located and easy-to-reach positions in the hospital restaurant, but butter stored in a fridge, therefore requiring more effort to obtain which reduced sales of butter and increase sales of margarine ${ }^{25}$; rearrangement of desserts in a hospital canteen so that low-calorie desserts (fruit and jelly) or high-calorie desserts (pies and cakes) were at the front in most accessible positions. ${ }^{27}$

Other successful pure choice architecture interventions including more than one element were

- Labelling + availabilityinterventions which changed dietary consumption in two studies. ${ }^{26} 4344$ Both these studies involved stipulating the proportion of meals on offer in a canteen that should be healthy (half in Lassen $e t a l$; a third in Holdsworth $e t a l$ ) and labelling these healthy meals as such. These are the only two pure choice architecture interventions which assessed dietary consumption. However, both had a high risk of bias over more than one domain.

- Labelling + proximity + prompting which changed purchasing behaviour in one study with a low risk of bias over most domains. ${ }^{30}$ In this study, all items on offer were labelled according to a traffic light system, green items were put at eye-level while red items were made less visible, and permanent signage and menu board changes were made to highlight healthy options.

- Availability + proximityintervention which changed purchasing behaviour in one study with a low risk of bias. ${ }^{31}$ In this study, a set of shelves stocked with snacks was placed on the check-out counter of a hospital canteen. In two phases, the shelves were stacked with $75 \%$ healthy and 25\% unhealthy snacks and for the other two phases these proportions were reversed. In addition, the shelves were rearranged so that the healthy snacks were at the top in two phases, and at the bottom (requiring stooping to access) in the other two phases. Both availability (proportion of healthy snacks on offer) and proximity (ease of obtaining the healthy snacks) had a positive effect on healthy snack purchasing.

Finally, Geaney et $a l^{24}$ used an intervention with several choice architecture elements which was successful in changing dietary consumption. In this study, menus were modified to increase availability of healthy options: highsalt products and processed meat were replaced with low-salt options, all desserts were fruit based, cooking methods with oil were limited. In addition, salt was removed in all cooking processes and from tables in the staff canteen (although it was available in small sachets from service). Nutritional information on salt reduction and a healthy diet was displayed in the canteen area. No sauces or accompaniments were added to any meals without the customer's consent, and extra salad and vegetable option was provided at no extra cost. This study had a low risk of bias and demonstrated an effect on intake of total sugars, total fats, saturated fats and salt as measured by 24 -hour dietary recall data. ${ }^{24}$

The only unsuccessful multicomponent choice architecture-only intervention was examined in Dorresteijn $e t$ $a l^{25}$ which used labelling + proximity + prompting. In this case, the two soups usually on offer in the restaurant were altered so that one option every day was reduced salt. Signs advertised that this soup 'contains $30 \%$ less salt and contributes to a healthy blood pressure'; however, this did not affect the number or ratio of normal salt to reducedsalt soup cups sold.

\section{Complex interventions including choice architecture}

As with the choice architecture-only interventions, most of the complex interventions included labelling elements in studied interventions while none included ambience or priming elements. In addition, none of the included studies of complex interventions examined presentation or sizing interventions. Where choice architecture interventions were implemented as part of complex interventions (usually involving other elements of behaviour change, eg, educational elements), there were many examples of effective interventions (table 4).

Complex interventions involving an availability choice architecture element were effective at changing dietary consumption in two studies. ${ }^{35}{ }^{46}$ In one of these studies, the other elements of the intervention were extensive 


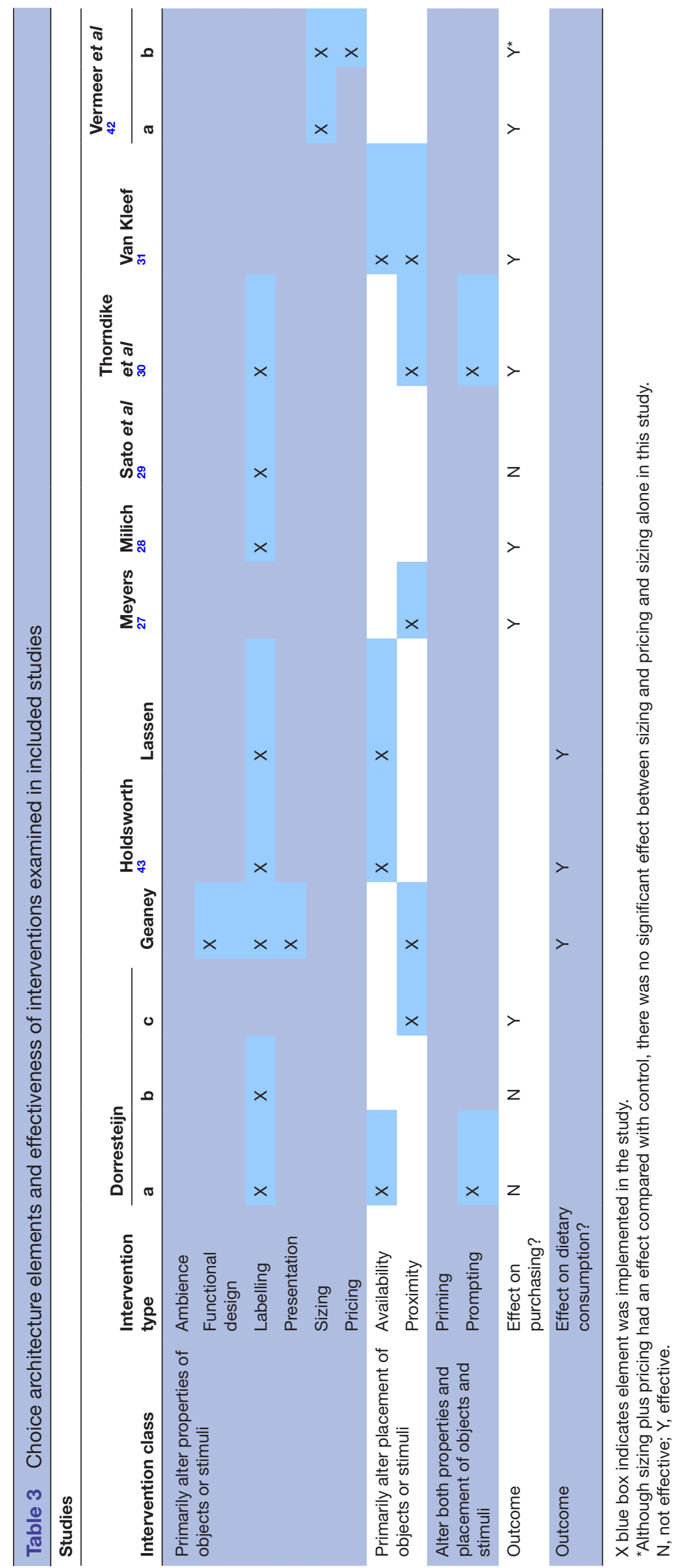

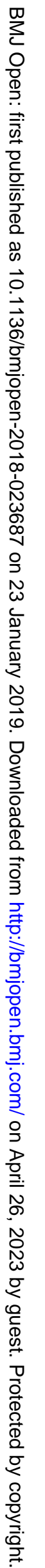


Table 4 Choice architecture elements included in complex interventions and their reported effectiveness in included studies

\begin{tabular}{|c|c|c|c|c|c|c|c|c|c|}
\hline \multicolumn{10}{|l|}{ Studies } \\
\hline $\begin{array}{l}\text { Intervention } \\
\text { class }\end{array}$ & $\begin{array}{l}\text { Intervention } \\
\text { type }\end{array}$ & Berefsord & ${ }_{48}^{K w a k}$ et al & ${ }_{34}^{\text {Lowe et al }}$ & $\begin{array}{l}\text { Macdonald } \\
\text { et al } \\
38\end{array}$ & $\begin{array}{l}\text { Racette } \\
\text { et al } \\
35\end{array}$ & $\begin{array}{l}\text { Sorensen } \\
\text { et al } \\
47\end{array}$ & $\begin{array}{l}\text { Sorensen } \\
\text { et al } \\
36\end{array}$ & $\underset{37}{\text { Stites et al }}$ \\
\hline \multirow{3}{*}{$\begin{array}{l}\text { Primarily alter } \\
\text { properties of } \\
\text { objects or stimuli }\end{array}$} & $\begin{array}{l}\text { Functional } \\
\text { design }\end{array}$ & & & & & & & & $x$ \\
\hline & Sizing & & & & & & & & \\
\hline & Pricing & & & $x$ & & & & & \\
\hline \multirow{2}{*}{$\begin{array}{l}\text { Primarily alter } \\
\text { placement of } \\
\text { objects or stimuli }\end{array}$} & Availability & $x$ & $X^{*}$ & $x$ & & $x$ & $x$ & & \\
\hline & Proximity & & & & & & & $x$ & $x$ \\
\hline \multirow[t]{2}{*}{ Outcome } & $\begin{array}{l}\text { Effect on } \\
\text { purchasing? }\end{array}$ & & & & $Y$ & & & & $\mathrm{Y}$ \\
\hline & $\begin{array}{l}\text { Effect on dietary } \\
\text { consumption? }\end{array}$ & Y & Y & $\mathrm{Y}$ & & $\mathrm{Y}$ & $\mathrm{Y}$ & $\mathrm{N}$ & \\
\hline
\end{tabular}

$\mathrm{X}$ blue box indicates element was implemented in the study.

*Kwak et al used an assets-based approach in which intervention worksites chose intervention elements that suited their context. Examples of actions given were classified as 'availability' and 'prompting'.

$\mathrm{N}$, not effective; Y, effective.

including pedometers, on-site WeightWatchers group meetings, an on-site group exercise programme, monthly lunchtime seminars, monthly newsletters, walking maps, team competitions, participation cards and participation rewards and weekly access to a registered dietitian/exercise specialist. ${ }^{35}$ The environmental component of the intervention was a weekly healthy snack cart that visited staff. $^{35}$ In the other study, the intervention included formation of employee advisory boards in each worksite to implement activities in their workplace including education and information about 5-a-Day, and a self-help manual provided to every employee to support them making healthy choices. In addition, the 'availability' component was providing more fruits and vegetables as part of the regular menus in the worksite canteens. ${ }^{46} \mathrm{In}$ both cases, it is difficult to draw much of a conclusion about the 'availability' components compared with the other components of the intervention.

Labelling + prompting was a successful combination when used alongside a complex intervention in one study ${ }^{38}$ and labelling + prompting + proximity was effective as part of a complex intervention in Sorensen et $a t^{77} .{ }^{4749}$ However, labelling + proximity, without prompting, was not effective in another study. ${ }^{36}{ }^{39-41}$ In all three studies, the other (non-choice architecture) elements of the interventions were direct educational activities, but none were particularly intensive suggesting labelling + prompting might work as pure choice architecture (labelling + prompting
+ proximity was also effective in the choice architecture-only studies)..$^{30}$

Labelling + pricing + availability was effective when used alongside a complex intervention in one study. ${ }^{34}$ In this study, canteens modified the recipes of some foods offered in order to reduce the energy density and introduced nutritional labels for all foods. In addition, some employees were given training in reducing the energy density of their diet and discounts on lower-energy-dense foods bought in the canteen. ${ }^{34}$ This study had high risk of attrition bias and possible evidence of selective outcome reporting. The study reported a significant reduction in total kilocalories purchased in the canteen and in the proportion of energy from fat. ${ }^{34}$

Stites $e t a l^{37}$ used a complex intervention with many choice architecture elements and was effective at changing behaviour. In this intervention, the participants received 'mindful eating training' and the hospital implemented an online preordering system for staff lunch. The preordering system had nutritional information displayed by all the choices, and for 4 of the 8-week intervention period, the employees received a discount for preordering rather than buying lunch direct in the canteen. Other elements included a preordering system which defaulted to the healthiest choice (requiring additional effort to select less healthy options). This study had low risk of bias and was effective at improving nutritional content of purchased lunches. 
In one study, in which the intervention had an effect on dietary consumption, choice architecture elements were chosen and implemented according to what suited the local context with examples relating to availability (which also changed behaviour in two other studies) and prompting (which is not studied in isolation in any other study). ${ }^{59}$

\section{Methodological quality of included studies}

The risk of bias of included studies is presented in tables 5 and 6 . High risk of bias was seen in two of the six RCTs. Racette et al, ${ }^{35}$ although using randomisation, only included two worksites, with quite different employee characteristics which may have introduced other sources of bias. ${ }^{36}$ Sorensel $e t a l^{369-41}$ collected more dietary data than was presented in the report, without clear justification for why specific outcomes were reported. Nearly all of the included randomised studies did not provide details on the process of randomisation (selection bias). Two studies ${ }^{37} 4245$ were at low risk of performance bias where blinding was not possible but unlikely to affect objective outcomes.

In the non-randomised studies, high risk of bias in more than one domain was seen in $4^{2634384344}$ of the 12 included studies. One study ${ }^{29}$ had errors in the numerical data presented which was cause for concern (number of entrees sold and mean number of entrees sold/day). Only two studies were judged at low risk of bias across all domains. ${ }^{2531}$ Half of the studies were at low risk of bias for confounding variables.

\section{DISCUSSION}

\section{Statement of principal findings}

Choice architecture interventions involving a proximity element appear to be frequently effective at changing behaviour. This was found in some studies that used proximity interventions alone or as part of choice architecture or complex interventions. Interventions including an availability element were generally reported to be successful at changing behaviour. However, none of the studies examined availability alone. A sizing intervention was effective in the only study identified examining this type of intervention.

There was no strong evidence for the effect of pricing on behavioural change in our review. No additional effect of pricing in a sizing and pricing intervention compared with sizing alone, and one complex intervention including pricing which was reported to be effective, but had a high risk of bias. Labelling alone was generally not effective at changing behaviour, although it was a popular addition to other interventions of which most were successful.

\section{Strengths and weaknesses of the study}

Because of the relatively small number of papers that we found during a scoping search, we made the decision to broaden the inclusion criteria in two ways. First, we have included studies in which complex interventions with non-choice architecture elements were implemented and it is not always possible to draw conclusions about the contribution of the choice architecture elements to the outcomes. Second, we have included studies in which not all the workplaces were healthcare settings. We did this because this gives us some evidence of interventions which are feasible in healthcare settings; however, because data were not disaggregated, we cannot be sure that outcomes were similar across the different sorts of workplaces included (ie, an element that was effective overall, may have been less effective or not effective in the healthcare settings; or an element that was not effective overall may have been effective in the healthcare settings). We conducted a comprehensive search across major electronic databases relevant to the topic of this review. Each included study in this review was comprehensively selected, assessed, data extracted and quality assessed by two review authors independently to minimise potential biases in the review process. Where data of relevance were missing, either to allow assessment of eligibility or at the data extraction stage and assessment of bias, the review authors (OO, LA, OU) contacted the study authors for further information.

\section{Strengths and weaknesses in relation to other studies, discussing important differences in results}

When Hollands $e t a l^{20}$ appraised the choice architecture literature in mid-2011, for the purposes of developing the typology we have used in this review, they noted that $40 \%$ of all study reports examined interventions which involved point-of-choice labelling and/or prompting elements. ${ }^{20}$ We found labelling and proximity elements were the most popular type of choice architecture employed in our included studies, both alone or in combination with other intervention elements. The difference might be due to the scope of the literature examined, we were restricted to those aiming to change dietary behaviour while Hollands et $a l^{19}$ looked more broadly at a range of behaviours.

Our study is specifically focused on employees of healthcare settings, a unique population who are likely to be more health conscious than the general population. For this reason, our findings are not necessarily generalisable outside these settings and others' findings may not be relevant for healthcare staff.

The finding of this review found mixed results for labelling interventions, suggesting that they are unlikely to be effective in isolation in these settings. A recent systematic review evaluating the effect of restaurant menu calorie labelling found 19 studies. Meta-analysis of these studies demonstrated an 18 calorie reduction in meals ordered when all studies were combined. However, when just the six controlled studies were examined, labelling was no longer associated with a significant difference in calories ordered.$^{60}$ Another systematic review found that menu labelling with calorie information alone did not reduce the number of calories selected or consumed, 


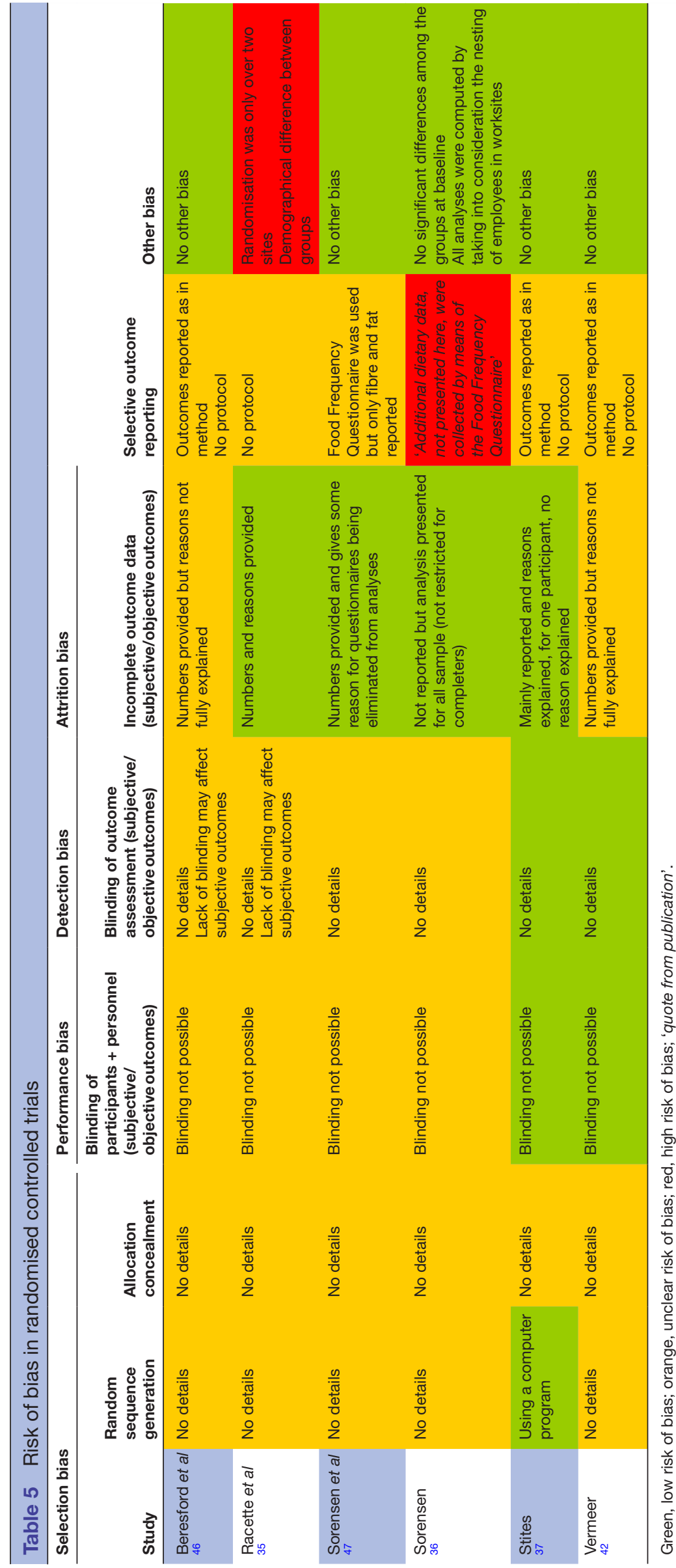

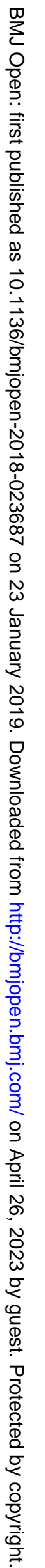




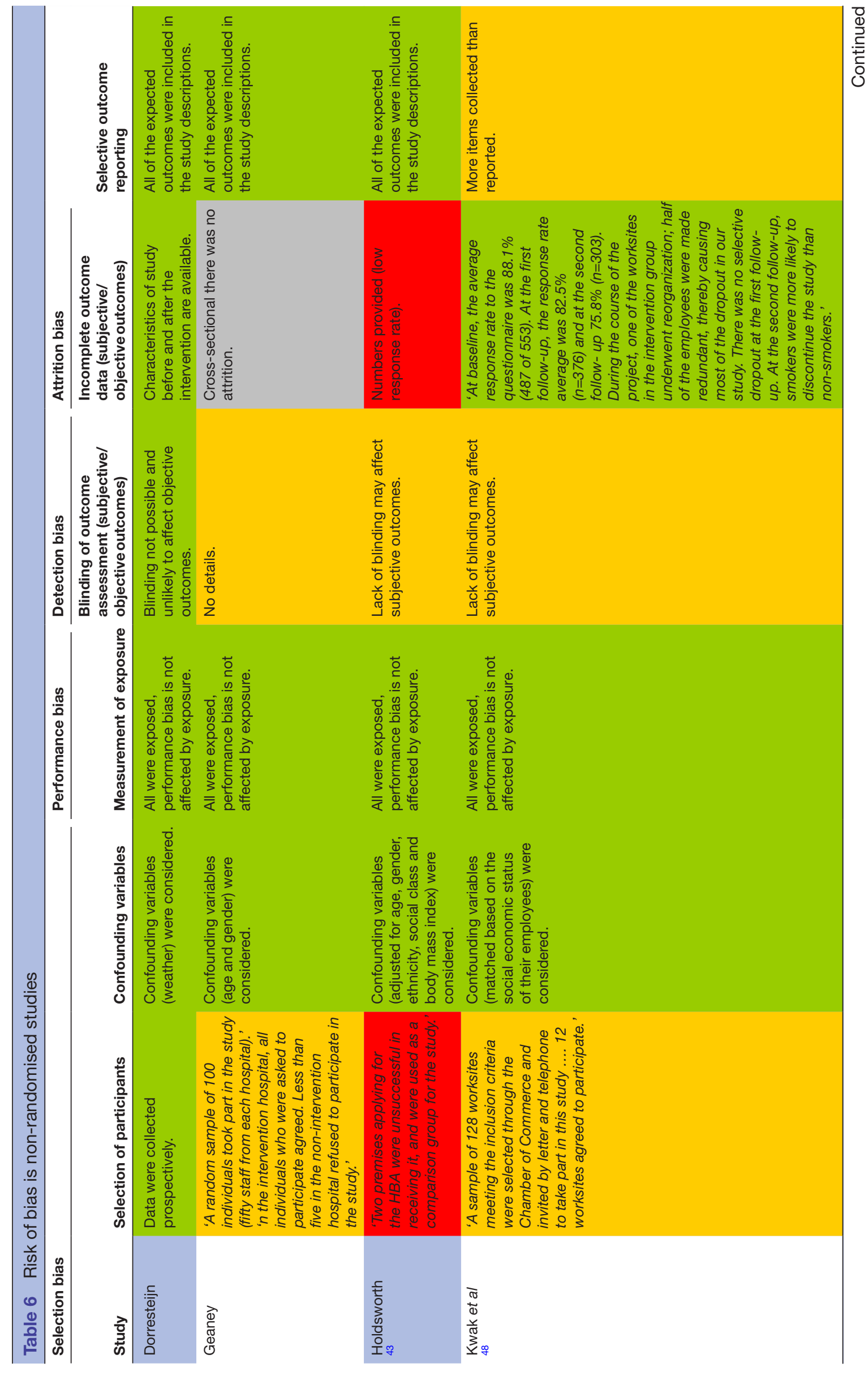

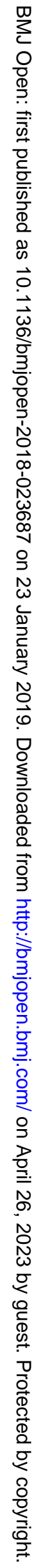




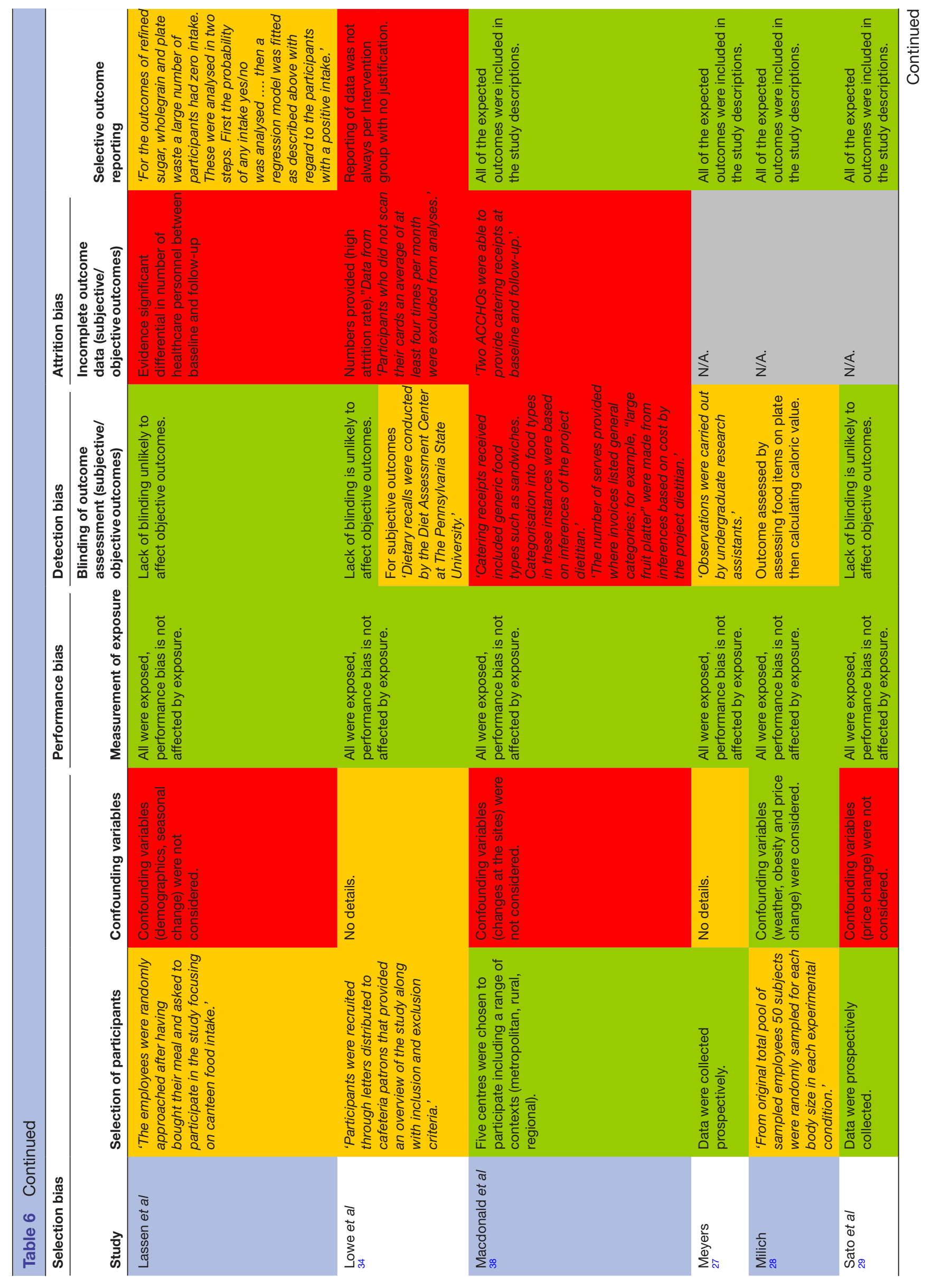

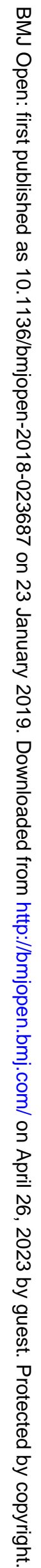



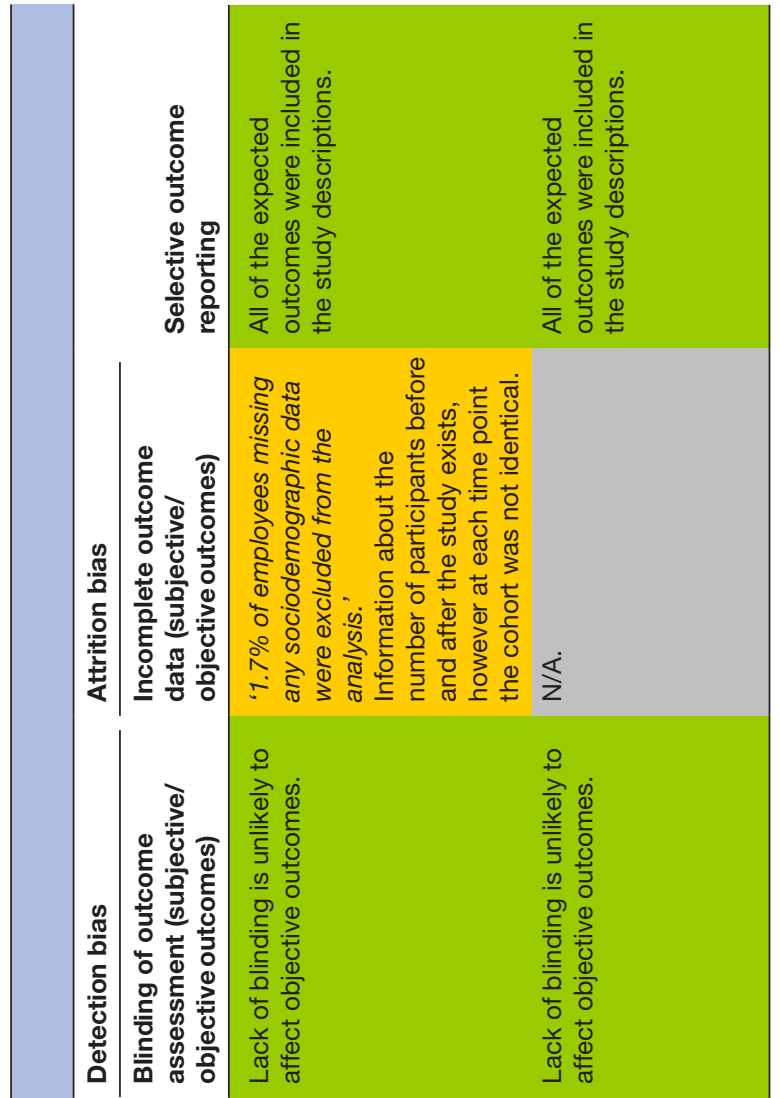

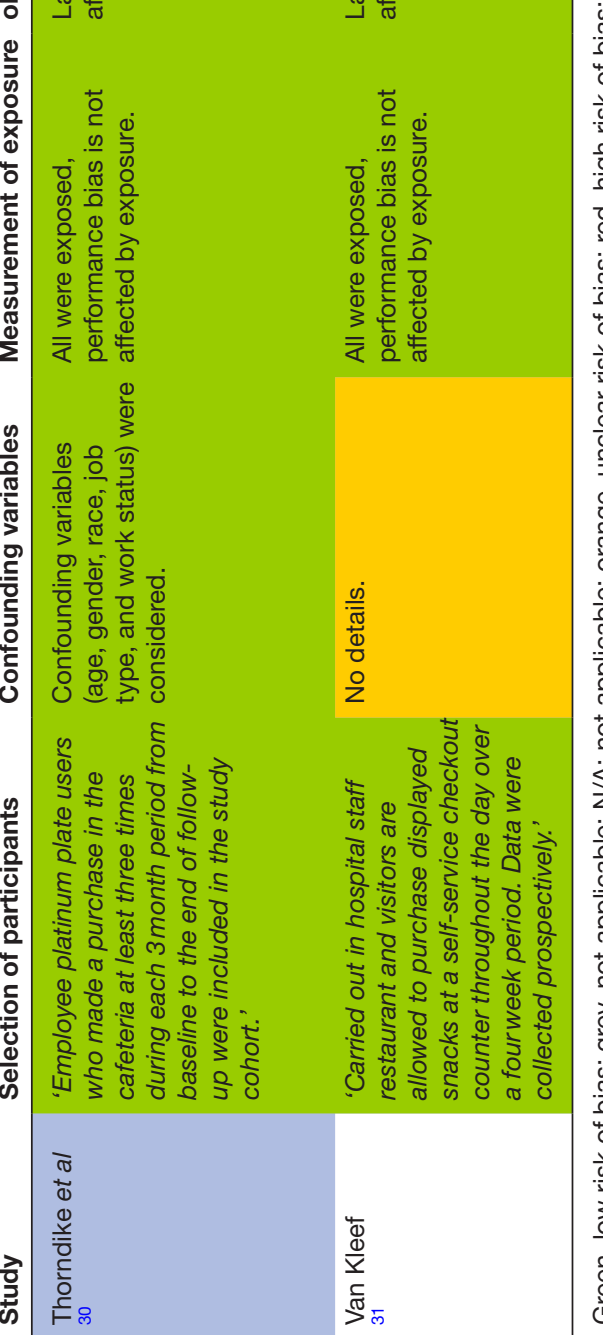

although the addition of information to assist consumers in applying nutritional information was effective. ${ }^{61}$ In a systematic review of RCTs that included food labels and excluded menu labelling, nine studies were identified and meta-analysis concluded that food labelling was effective at changing dietary behaviour although not at reducing calorie consumption. ${ }^{62}$ Menu energy labelling across socioeconomic groups was evaluated in a recent review. ${ }^{63}$ The findings suggested that any positive benefit of this kind of labelling may only apply to higher socioeconomic groups. ${ }^{63}$ The findings of this review in the context of previous literature suggest that labelling alone should not be recommended for implementation to improve healthy food and drink purchasing of healthcare staff.

A large systematic review evaluated supermarket and grocery store interventions to increase consumption of healthy food and/or beverages. Analysis of 42 studies found that consumers responded to economic incentives including discounts, vouchers and subsidies. ${ }^{64}$ Similarly, a systematic review of interventions at point-of-sale to encourage healthier food purchasing found evidence for monetary incentives as effective at changing behaviour, but that there was no strong evidence for the other intervention types they examined. ${ }^{65}$ We found mixed evidence on pricing in healthcare settings in this review.

A systematic review of interventions carried out in restaurant settings to promote healthy eating stated that the most effective interventions were point-of-purchase information with increased availability of healthy choices. ${ }^{66}$ We also found that increasing availability of healthy options alongside other intervention elements was a successful strategy for driving behaviour change in healthcare settings.

\section{Meaning of the study: possible explanations and implications for clinicians and policymakers}

On the basis of this systematic review, we were able to recommend some general principles that are likely to be effective when designing choice architecture interventions for NHS organisations to PHE. These are 'proximity' interventions in which behavioural options are made easier or harder to engage with, requiring reduced or increased effort and 'availability' interventions in which healthy behavioural options are added within a given microenvironment. In addition, we are able to suggest 'sizing' interventions in which the size or quantity of the product on offer is changed based on one effective study with low risk of bias. Finally, we can recommend specific examples of choice architecture interventions that have been effective in studies with low risk of bias. These recommendations are made in a companion format (please see supplementary material 3), designed for the audience who make decisions about catering in NHS organisations.

\section{Other outcomes relevant to decision-makers}

We examined primary outcomes relating to dietary consumption and purchasing of food and drink. However, outcomes that are important to decision-makers include 
customer satisfaction and profitability. One of our included studies which examined various arrangements and assortments of snacks on offer at the checkout counter in a hospital staff restaurant found in a survey of 92 participants that the more visible the healthy snacks were in terms of location (ie, on top shelves) and proportion (ie, $75 \%$ healthy vs $25 \%$ healthy) the more attractive the entire selection was perceived to be. ${ }^{31}$ Another included study noted that the presentation of caloric values of the food significantly decreased the total number of calories bought without significantly affecting the total money spent. $^{28}$

In a study of nine early adopters of the Hospital Healthier Food Initiative and the Health and Sustainability Guidelines in the USA, the main barriers to implementation were reported to be customer complaints, a shortage of food and drinks that met the requirements of the Initiative/Guidelines and concern over profitability. However, most respondents had been able to overcome these barriers and it was noted that customer volumes and sales were reported to have increased subsequent to implementation which offset initial investments necessary to successfully meet the requirements of the Initiative/ Guidelines. ${ }^{16}$

A study in which a 'healthful food station' was introduced to a worksite cafeteria in an academic medical centre in the USA found that some customers reported that they used the cafeteria more often due to the presence of the station. Others had only started using the cafeteria because the station had been introduced. This study also found that the healthful food station generated gross profit. ${ }^{56}$

\section{Unanswered questions and future research}

Reporting of studies was generally poor. For instance, both randomised and non-randomised studies did not generally report on domains that may lead to selection bias. We are generally unsure whether subjective outcomes were collected by blinded assessors which may lead to detection bias. Overall, the methodological quality of included studies was low and future research should clearly report on this. Therefore, the results of this review should be interpreted with caution.

In healthcare settings, increasing availability of healthy options alongside other intervention elements was found to be successful in improving behaviour (specifically increasing consumption of fruit and vegetables). However, we do not know the effect of increasing availability alone.

We could not come to a clear conclusion whether a pricing element is clearly successful in improving healthy food and drink purchasing and consumption in healthcare settings.

No studies investigated the effect of ambience or priming elements on modifying dietary behaviour in healthcare settings.

Acknowledgements The authors thank Aileen Clarke, Warwick Medical School; Ruth Breese, South Warwickshire NHS Foundation Trust; Elizabeth Atherton,
Food for Life Programme, Soil Association; Laura Brown, Sarah Golding and Tim Chadborn, Public Health England, all of whom gave comments and feedback that have supported this work.

Contributors LA-K and 00 designed the protocol. LA-K, 00 and SJ designed and ran the searches. LA and 00 performed the initial screening. LA-K, 00 and OAU screened full-text articles. LA-K, 00, OAU and RW extracted data from included studies. LA-K and 00 synthesized extracted data and wrote the first draft of the manuscript. All authors contributed to the final submitted manuscript.

Funding This piece of research was funded by Public Health England Behavioural Insights Team who gave feedback on the study protocol. LA and 00 are supported by the National Institute of Health Research (NIHR) Collaboration for Applied Health Research and Care West Midlands initiative. RW was supported by University of Warwick through its Global Research Priority on Food. SJ was supported by the University of Warwick.

Disclaimer The funder had no role in the collection, analysis or interpretation of data, in the writing of the report or decision to submit the article for publication. The views expressed are those of the authors and not necessarily those of the NHS, the NIHR or the Department of Health.

Competing interests None declared.

Patient consent Not required.

Provenance and peer review Not commissioned; externally peer reviewed.

Data sharing statement No additional data available.

Open access This is an open access article distributed in accordance with the Creative Commons Attribution 4.0 Unported (CC BY 4.0) license, which permits others to copy, redistribute, remix, transform and build upon this work for any purpose, provided the original work is properly cited, a link to the licence is given, and indication of whether changes were made. See: https://creativecommons.org/ licenses/by/4.0/.

\section{REFERENCES}

1. Newton JN, Briggs ADM, Murray CJL, et al. Changes in health in England, with analysis by English regions and areas of deprivation, 1990-2013: a systematic analysis for the Global Burden of Disease Study 2013. The Lancet 2015;386:2257-74.

2. Ng M, Fleming T, Robinson M, et al. Global, regional, and national prevalence of overweight and obesity in children and adults during 1980-2013: a systematic analysis for the Global Burden of Disease Study 2013. The Lancet 2014;384:766-81.

3. Scarborough P, Bhatnagar P, Wickramasinghe KK, et al. The economic burden of ill health due to diet, physical inactivity, smoking, alcohol and obesity in the UK: an update to 2006-07 NHS costs. J Public Health 2011;33:527-35.

4. NHS Digital. Secondary Health Survey for England 2015: adult overweight and obesity. 2016 https://digital.nhs.uk/catalogue/ PUB20562 (Accessed Nov 2017).

5. Butland B, Jebb S, Kopelman P, et al. Tackling obesities: future choices-project report department of innovation, universities and skills. . London, 2007:10. 17.

6. Shrestha N, Pedisic Z, Neil-Sztramko S, et al. The impact of obesity in the workplace: a review of contributing factors, consequences and potential solutions. Curr Obes Rep 2016;5:344-60.

7. Koepp GA, Snedden BJ, Levine JA. Workplace slip, trip and fall injuries and obesity. Ergonomics 2015;58:674-9.

8. Flint SW, Snook J. Disability discrimination and obesity: the big questions? Curr Obes Rep 2015;4:504-9.

9. England NHS. Simon Stevens announces major drive to improve health in NHS workplace. 2015 https://www.england.nhs.uk/2015/ 09/nhs-workplace/ (Accessed Nov 2017).

10. Blake H, Mo PK, Lee S, et al. Health in the NHS: lifestyle behaviours of hospital employees. Perspect Public Health 2012;132:213.

11. Kyle RG, Neall RA, Atherton IM. Prevalence of overweight and obesity among nurses in Scotland: A cross-sectional study using the Scottish Health Survey. Int J Nurs Stud 2016;53:126-33.

12. Blake $H$, Harrison $C$. Health behaviours and attitudes towards being role models. Br J Nurs 2013;22:86-94.

13. Dalton MB. Implementing NICE obesity guidance for staff: an NHS trust audit. Occup Med 2015;65:78-85.

14. Young A. Innovation within a national health care system. Surgery 2017;161:1179-82.

15. World Health Organization. Healthy workplaces: a global framework and model: review of literature and practices. Geneva: World Health Organization, 2010. 
16. Jilcott Pitts SB, Graham J, Mojica A, et al. Implementing healthier foodservice guidelines in hospital and federal worksite cafeterias: barriers, facilitators and keys to success. J Hum Nutr Diet 2016;29:677-86.

17. NHS England. Commissioning for Quality and Innovation (CQUIN) indicator specification 2017-2019. 2017a https://www.england.nhs. uk/publication/cquin-indicator-specification/ (accessed Dec 2017).

18. Al-Khudairy L, Uthman $\mathrm{O}$, Johnson $\mathrm{S}$, et al. Behavioural interventions to increase healthier purchasing and/or consumption of food and drink by NHS staff. PROSPERO 2017:CRD42017064872.

19. Hollands GJ, Shemilt I, Marteau TM, et al. Altering microenvironments to change population health behaviour: towards an evidence base for choice architecture interventions. BMC Public Health 2013;13:1218.

20. Bank W. High Income. 2017 https://data.worldbank.org/incomelevel/high-income (Accessed Nov 2017).

21. Willett W. Nutritional epidemiology: Oxford University Press, 2012.

22. Higgins JPT SG. Cochrane handbook for systematic reviews of interventions version 5.1.0: The Cochrane Collaboration, 2011.

23. Kim SY, Park JE, Lee YJ, et al. Testing a tool for assessing the risk of bias for nonrandomized studies showed moderate reliability and promising validity. J Clin Epidemiol 2013;66:408-14.

24. Geaney F, Harrington J, Fitzgerald AP, et al. The impact of a workplace catering initiative on dietary intakes of salt and other nutrients: a pilot study. Public Health Nutr 2011;14:1345-9.

25. Dorresteijn JA, van der Graaf Y, Zheng K, et al. The daily 10 kcal expenditure deficit: a before-and-after study on low-cost interventions in the work environment. BMJ Open 2013;3:e002125.

26. Lassen AD, Beck A, Leedo $E$, et al. Effectiveness of offering healthy labelled meals in improving the nutritional quality of lunch meals eaten in a worksite canteen. Appetite 2014;75:128-34.

27. Meyers AW. Food accessibility and food choice. Arch Gen Psychiatry 1980;37:1133-5.

28. Milich R, Anderson J, Mills M. Effects of visual presentation of caloric values on food buying by normal and obese persons. Percept Mot Skills 1976;42:155-62.

29. Sato JN, Wagle A, McProud L, et al. Food label effects on customer purchases in a hospital cafeteria in Northern California. Journal of Foodservice Business Research 2013;16:155-68.

30. Thorndike AN, Riis J, Sonnenberg LM, et al. Traffic-light labels and choice architecture: promoting healthy food choices. Am J Prev Med 2014;46:143-9.

31. van Kleef E, Otten K, van Trijp HC. Healthy snacks at the checkout counter: a lab and field study on the impact of shelf arrangement and assortment structure on consumer choices. BMC Public Health 2012;12:1072.

32. Levy DE, Riis J, Sonnenberg LM, et al. Food choices of minority and low-income employees: a cafeteria intervention. Am J Prev Med 2012;43:240-8.

33. Thorndike AN, Sonnenberg L, Riis J, et al. A 2-phase labeling and choice architecture intervention to improve healthy food and beverage choices. Am J Public Health 2012;102:527-33.

34. Lowe MR, Tappe KA, Butryn ML, et al. An intervention study targeting energy and nutrient intake in worksite cafeterias. Eat Behav 2010;11:144-51.

35. Racette SB, Deusinger SS, Inman CL, et al. Worksite Opportunities for Wellness (WOW): effects on cardiovascular disease risk factors after 1 year. Prev Med 2009;49:108-14.

36. Sorensen G, Stoddard A, Peterson K, et al. Increasing fruit and vegetable consumption through worksites and families in the treatwell 5-a-day study. Am J Public Health 1999;89:54-60.

37. Stites SD, Singletary SB, Menasha A, et al. Pre-ordering lunch at work. results of the what to eat for lunch study. Appetite 2015;84:88-97.

38. MacDonald C, Genat B, Thorpe S, et al. Establishing healthpromoting workplaces in Aboriginal community organisations: healthy eating policies. Aust J Prim Health 2016;22:239-43.

39. Hunt MK, Lederman R, Potter S, et al. Results of employee involvement in planning and implementing the Treatwell 5-a-Day work-site study. Health Educ Behav 2000;27:223-31.

40. Hunt MK, Lederman R, Stoddard A, et al. Process tracking results from the treatwell 5-a-day worksite study. Am J Health Promot 2000;14:179-87.

41. Sorensen G, Hunt MK, Cohen N, et al. Worksite and family education for dietary change: the Treatwell 5-a-Day program. Health Educ Res 1998;13:577-91.

42. Vermeer WM, Steenhuis IH, Leeuwis $\mathrm{FH}$, et al. Small portion sizes in worksite cafeterias: do they help consumers to reduce their food intake? Int J Obes 2011;35:1200-7.
43. Holdsworth M, Raymond NT, Haslam C. Does the heartbeat award scheme in England result in change in dietary behaviour in the workplace? Health Promot Int 2004;19:197-204.

44. Holdsworth M, Haslam C, Raymond NT. Does the heartbeat award scheme change employees' dietary attitudes and knowledge? Appetite 2000;35:179-88.

45. Vermeer WM, Leeuwis FH, Koprulu S, et al. The process evaluation of two interventions aimed at portion size in worksite cafeterias. $J$ Hum Nutr Diet 2012;25:180-8.

46. Beresford SA, Thompson B, Feng Z, et al. Seattle 5 a day worksite program to increase fruit and vegetable consumption. Prev Med 2001;32:230-8.

47. Sorensen G, Morris DM, Hunt MK, et al. Work-site nutrition intervention and employees' dietary habits: the treatwell program. Am J Public Health 1992;82:877-80.

48. Kwak L, Kremers SP, Visscher TL, et al. Behavioral and cognitive effects of a worksite-based weight gain prevention program: the NHFNRG in balance-project. J Occup Environ Med 2009;51:1437-46.

49. Sorensen G, Hunt MK, Morris DH, et al. Promoting healthy eating patterns in the worksite: the Treatwell intervention model. Health Educ Res 1990;5:505-15.

50. Cremaschini M, Moretti R, Brembilla G, et al. [Assessment of the impact over one year of a workplace health promotion programme in the province of Bergamo]. Med Lav 2015;106:159-71.

51. Glasgow RE, Terborg JR, Hollis JF, et al. Take heart: results from the initial phase of a work-site wellness program. Am J Public Health 1995;85:209-16.

52. Verweij LM, Proper KI, Weel AN, et al. The application of an occupational health guideline reduces sedentary behaviour and increases fruit intake at work: results from an RCT. Occup Environ Med 2012;69:500-7.

53. Vyth EL, Steenhuis IH, Heymans MW, et al. Influence of placement of a nutrition logo on cafeteria menu items on lunchtime food choices at dutch work sites. J Am Diet Assoc 2011;111:131-6.

54. Alinia S, Lassen AD, Krogholm KS, et al. A workplace feasibility study of the effect of a minimal fruit intervention on fruit intake. Public Health Nutr 2011:14:1382-7.

55. Dawson J, Dwyer JJ, Evers S, et al. Eat smart! Workplace Cafeteria Program evaluation of the nutrition component. Can J Diet Pract Res 2006;67:85-90.

56. Kimathi AN, Gregoire MB, Dowling RA, et al. A healthful options food station can improve satisfaction and generate gross profit in a worksite cafeteria. J Am Diet Assoc 2009;109:914-7.

57. Van Hulst A, Barnett TA, Déry V, et al. Health-promoting vending machines: evaluation of a pediatric hospital intervention. Can J Diet Pract Res 2013;74:28-34.

58. Hurd J, Mitchell H, Hawkins $\mathrm{C}$, et al. The get on track challenge: an effective physical activity and healthy eating program for workplaces. Obesity Reviews 2014;15:221

59. Kwak L, Kremers SP, Candel MJ, et al. span>Changes in skinfold thickness and waist circumference after 12 and 24 months resulting from the NHF-NRG In Balance-projectspan>. Int J Behav Nutr Phys Act 2010;7:26.

60. Long MW, Tobias DK, Cradock AL, et al. Systematic review and meta-analysis of the impact of restaurant menu calorie labeling. Am J Public Health 2015;105:e11-e24.

61. Sinclair SE, Cooper M, Mansfield ED. The influence of menu labeling on calories selected or consumed: a systematic review and metaanalysis. J Acad Nutr Diet 2014;114:1375-88.

62. Cecchini M, Warin L. Impact of food labelling systems on food choices and eating behaviours: a systematic review and metaanalysis of randomized studies. Obes Rev 2016;17:201-10.

63. Sarink D, Peeters A, Freak-Poli R, et al. The impact of menu energy labelling across socioeconomic groups: a systematic review. Appetite 2016;99:59-75.

64. Adam A, Jensen JD. What is the effectiveness of obesity related interventions at retail grocery stores and supermarkets? -a systematic review. BMC Public Health 2016;16:1247.

65. Liberato SC, Bailie R, Brimblecombe J. Nutrition interventions at point-of-sale to encourage healthier food purchasing: a systematic review. BMC Public Health 2014;14:919.

66. Espino JNV, Guerrero N, Rhoads N, et al. Peer reviewed: communitybased restaurant interventions to promote healthy eating: a systematic review. Prev. Chronic Dis 2015.

67. Geaney F, Harrington J, Fitzgerald A, et al. The impact of a workplace catering initiative on dietary intakes of salt and other nutrients: a pilot study. Public Health Nutr 2011;14:1345-9. 